\title{
Endometrial cancer implanted within a cesarean section scar.
}

\section{$\operatorname{AUTHOR}(S)$ :}

Baba, Tsukasa; Mandai, Masaki; Yamanishi, Yukio; Suzuki, Ayako; Kang, Hyun Sook; Konishi, Ikuo

\section{CITATION:}

Baba, Tsukasa ... [et al]. Endometrial cancer implanted within a cesarean section scar. The journal of obstetrics and gynaecology research 2011, 37(3): 245-249

\section{ISSUE DATE:}

2011-02-11

URL:

http://hdl.handle.net/2433/197312

\section{RIGHT:}

This is the peer reviewed version of the following article: Baba, T., Mandai, M., Yamanishi, Y., Suzuki, A., Kang, H. S. and Konishi, I. (2011), Endometrial cancer implanted within a cesarean section scar. Journal of Obstetrics and Gynaecology Research, 37: 245-249, which has been published in final form at http://dx.doi.org/10.1111/j.1447-0756.2010.01381.x; This is not the published version. Please cite only the published version.; この論文は出版社版でありません。引用の際 には出版社版をご確認ご利用ください。 


\section{An endometrial cancer implant within a cesarean section scar}

Tsukasa Baba M.D., Masaki Mandai M.D., Yukio Yamanishi M.D., Ayako Suzuki M.D., Hyun Sook Kang M.D., and Ikuo Konishi M.D.

Department of Gynecology and Obstetrics, Kyoto University Graduate School of Medicene, Kyoto, JAPAN

54 Shogoin Kawahara-cho, Sakyo-ku, Kyoto, Kyoto 606-8507, JAPAN

Phone; 81-75-751-3269, Fax; 81-75-761-3967

babatsu@kuhp.kyoto-u.ac.jp 


\begin{abstract}
Several reports have documented adenocarcinoma arising from endometriotic implants within the cesarean section (C-S) scar on the serosal surface of the uterus. However, endometrial cancer invading the C-S scar from the uterine cavity has not been described. We report a case of a grade-1 endometrioid adenocarcinoma “drop” lesion invading a previous C-S scar with resultant cervical stromal invasion. Using both MR images and a thorough review of the pathology, the tumor at the C-S scar was determined to be an implant derived from a primary lesion at the uterine fundus. With increases in the incidence of both endometrial cancer and births by C-S, it is likely we will encounter more cases of iatrogenic implants of endometrial cancers in C-S scars.
\end{abstract}

Keywords: endometrial cancer, cesarean section, implant 


\section{INTRODUCTION}

Uterine corpus cancer is the leading cause of malignant gynecological disease with more than 40,000 cases diagnosed per year in the US and the number of patients bearing this disease steadily increasing ${ }^{1}$. In Japan, the incidence has been increasing and is predicted to be the leading cause of gynecological malignancy in the next decade.

Placental attachment to the cesarean section (C-S) scar is observed in $20 \%$ of placenta previas, and placenta previa-accreta occurs 3-14 times more frequently in women who have had a C-S compared to those not ${ }^{2}$. This suggests that the C-S scar is more prone to trophoblastic invasion and has a susceptibility to tumor invasion as well.

While there are reports of both endometrioid and clear cell adenocarcinomas arising from endometriotic implants within the C-S scar on the peritoneal surface of the uterus $^{3,4}$, ours is the first of an endometrial cancer “drop” lesion invading a C-S scar with the primary lesion being a small lesion at the uterine fundus. As the C-S rate has increased from $21 \%$ to $31 \%$ over the last decade ${ }^{5}$, we are likely to encounter endometrial cancers invading C-S scars more frequently. This may require new therapeutic strategies to address this specific scenario.

\section{CASE}

A 43- year-old obese (BMI 30) postmenopausal woman (gravida 1, para 1) presented to our hospital because of intermittent abnormal vaginal bleeding lasting for one month. Her obstetrical history was significant for cesarean delivery of a $3400 \mathrm{~g}$ male baby via a low transverse uterine incision due to labor dystocia at 29 years of age. Physical exam showed a small amount of bloody discharge from the uterus and an 8-10 week size uterus. Ultrasonography demonstrated a $3 \mathrm{~cm}$ hyperechoic intrauterine lesion at the uterine isthmus and endometrial biopsy was positive for adenocarcinoma. 
Subsequent hysteroscopy revealed a protruding tumor with atypical vessels in the cervical canal and diffuse papillary tumor mainly covering the left-anterior wall just above the internal os. Thorough exploration inside of uterus was prevented by the massive growth of this tumor. Endometrial curettings demonstrated a grade 1 endometrioid adnocarcinoma. Serum CA125 level was elevated to $64.8 \mathrm{U} / \mathrm{ml}$ (normal range <35), while CEA $0.8 \mathrm{ng} / \mathrm{ml}(<2.5)$ and CA19-9 $36.8 \mathrm{U} / \mathrm{ml}(<37)$ were within normal range.

Sagittal T-2 weighted magnetic resonance (MR) images demonstrated a thin low anterior uterine wall and bulging of the endometrial cavity at the uterine isthmus (Figure 1A). A T-2 low intensity lesion was observed to occupy this bulging from the lower uterine cavity to the cervical canal and suggested myometrial invasion (Figure 1B). However, on the T1-weighted dynamic images (Figure 1C), the border between the tumor and the myometrium was smooth and the contrast enhancement of the isthmic tumor was poor which suggested the myometrial invasion was superficial. In addition to the isthmic lesion, a small intrauterine polypoid low intensity lesion was detected at the uterine fundus (Figure 1A). Computed tomography did not describe any lymphadenopathy or extrauterine metastases.

The patient underwent a modified radical hysterectomy, bilateral salpingo-oophorectomy, and pelvic and paraaortic lymphadenectomy. As intraoperative peritoneal cytology was positive, partial omentectomy was performed although there was no gross evidence of dissemination or metastasis at the time of surgery.

On gross examination, the uterus was enlarged (Figure 2A), and the tumor measured 55mm x 50mm and was located predominantly in the uterine isthmus with a portion of the tumor encroaching the cervix (Figure 2B). There were also polypoid 
tumors protruding into the endometrial cavity at the uterine fundus (Figure 2C). The fundal and isthmic lesions were separate and the endometrial surface between these tumor sites was obviously smooth and tumor-free. On the cut surface, the tumor was yellowish to whitish in color, and the isthmic tumor appeared to invade the uterine myometrium at the site of the cesarean scar, while the fundal tumor showed no invasive features.

Microscopically, a well-differentiated grade-1 endometrioid adenocarcinoma was identified in both the fundal (Figure 3A) and isthmic (Figure 3B) tumors. The fundal tumor was observed adjacent to normal secretory phase endometrium and endometrial hyperplasia but no myometrial invasion or desmoplastic stromal reaction was detected (Figure 3C). In contrast, the endometrium at the C-S scar was very thin and composed only of a single-layer of epithelial cells without normal endometrial stromal cells (Figure 3D). The isthmic tumor invaded the myometrium at the C-S section site, but also lacked a desmoplastic stromal reaction, giving the impression that the tumor did not originate at this site but was an implant from another source. Additionally, the tumor implant encroached the upper wall of the cervix (Figure 3E) and demonstrated lymphovascular space involvement (Figure 3F). Lymph node metastasis was not observed, and the tumor was designated as pT3aN0M0. Adjuvant chemotherapy with cisplatin and adriamycin was employed and there has been no recurrence to date.

\section{DISCUSSION}

We report a case of endometrial carcinoma in which a cancer lesion existed both in the endometrial fundus and the C-S scar in the isthmus independently. The pathological features of both tumors were similar, although these were separate and had no direct connection to one another. There are theoretically three possibilities as 
regards to the origin of these two lesions: 1) both are synchronous primary tumors, 2) the tumor at the C-S scar is the primary tumor with the fundal lesion a metastatic implant, or our strongest suspicion, 3) the fundal tumor is the primary tumor with a metastatic lesion to the C-S scar. We speculate that this grade-1 endometrioid adenocarcinoma arose from the endometrium at the uterine fundus and then "dropped down” to the isthmus as an implant on the C-S scar. Our assumption is based on these findings:1) pathologically, the lesion in the endometrium appeared to be primary since it was accompanied with endometrial hyperplasia in a thickened normal endometrium, 2) the C-S scar was only covered with a single layer of epithelium and could not be regarded as the tumor origin, and 3) the C-S scar can be regarded as "seed-soil” for tumor implantation. $\quad$ C-S scar site is reported in a hypermetabolic condition ${ }^{6}$ showing neoangiogenesis with remarkable VEGF expression7, although it is not confirmed such state will be kept for long. However, recurrence of endometrial cancers due to “seeding” during primary surgery has been actually reported in a laparotomy incision ${ }^{8}$, a laparoscopy-trocar site ${ }^{9}$, and within the scar following the marsupialization of a benign Bartholin's cyst ${ }^{10}{ }^{--}$each of these suggesting that the surgical scar can serve as an iatrogenic receptor for endometrial cancer implants. Scar endometriosis in the peritoneal cavity is infamous as an iatrogenic precursor of several malignant transformations ${ }^{3,4,11}$. Although our case differs in that there was no pathological evidence of endometriosis, C-S scar inside of uterus should be regarded as another site of cancer involvement.

Although the International Federation of Obstetricians and Gynecologists (FIGO) staging of uterine corpus is designed to reflect tumor biology and patterns of spread, a variety of risk factors besides FIGO staging system have been demonstrated, such as pathological grade, depth of myometrial invasion, and lymphovascular space involvement (LVSI). Endometrial cancer arising in the uterine isthmus (UIE), which 
accounts for only 3-4\% of uterine cancers, is a unique form with a poor prognosis compared with those arising in the middle or upper parts of the uterine corpus (UCE) ${ }^{12}$. When compared to UCE, UIE is more frequently associated with high risk factors: deep-myometrial invasion (38.5\% vs $12.1 \%$ ), positive peritoneal cytology (38.5\% vs 15.2\%), and LVSI (46.2\% vs $21.2 \%)^{12}$. LVSI is an independent risk factor of endometrial cancers for metastasis and relapse ${ }^{13}$, and direct invasion of the upper cervical wall is significantly correlated with LVSI ${ }^{14}$. In this case, although primary lesion of the fundus was minimal, tumor showed unfavorable features to involve the cervix and lymphatic flows, possibly because of the presence of the C-S scar.

It is well-known that placenta accreta-previa occurs in the C-S scar in up to $14 \%$ of C-S, while it occurs only in $1-5 \%$ in the intact uterus ${ }^{2}$, suggesting that the C-S scar may be a susceptible site for myometrial invasion. Our report suggests that the C-S scar may also share the propensity for myometrial invasion with endometrial cancers and may facilitate cervical invasion and/or LVSI even when the grade of the tumor lacks aggressive features. Cervical invasion of endometrial cancer cannot be clinically ignored as the 5-year survival rate of stage II endometrial cancer is $78.3 \%$, much less than the $89.6 \%$ of patients with stage I disease (Hazard ratio; 2.2$)^{15}$. These results may evoke a need to perform a conventional or modified radical hysterectomy in cases with C-S scar involvement, for regarding the subsequent invasion into myometrium, cervix, and/or lymphovascular space.

\section{Acknowledgement}

The authors declare no conflict of interests and also thank Dr. Jason C Barnett for thoroughly reviewing the manuscript. 


\section{REFFERENCES}

[1] Jemal A, Siegel R, Ward E, et al. Cancer statistics, 2008. CA Cancer J Clin. 2008;58(2):71-96.

[2] Laughon SK, Wolfe HM, Visco AG. Prior cesarean and the risk for placenta previa on second-trimester ultrasonography. Obstet Gynecol. 2005;105(5 Pt 1):962-5.

[3] Markopoulos C, Gogas H, Eleftheriou G, Floros D. Endometrioid carcinoma arising in a scar of caesarean section. Case report. Eur J Gynaecol Oncol. 1996;17(6):520-1.

[4] Park SW, Hong SM, Wu HG, Ha SW. Clear cell carcinoma arising in a Cesarean section scar endometriosis: a case report. J Korean Med Sci. 1999;14(2):217-9.

[5] MacDorman MF, Menacker F, Declercq E. Cesarean birth in the United States: epidemiology, trends, and outcomes. Clin Perinatol. 2008;35(2):293-307, v.

[6] Cheng YM, Ho CL, Chiu NT, Hsu KF. Cesarean section scar mimicking uterine malignant neoplasm at positron emission tomography/computed tomography. J Minim Invasive Gynecol. 2009;16(3):372-4.

[7] Pollio F, Staibano S, Mascolo M, et al. Uterine dehiscence in term pregnant patients with one previous cesarean delivery: growth factor immunoexpression and collagen content in the scarred lower uterine segment. Am J Obstet Gynecol. 2006;194(2):527-34.

[8] Macias V, Baiotto B, Pardo J, Munoz F, Gabriele P. Laparotomy wound recurrence of endometrial carcinoma. Gynecol Oncol. 2003;91(2):429-34.

[9] Sanjuan A, Hernandez S, Pahisa J, et al. Port-site metastasis after laparoscopic surgery for endometrial carcinoma: two case reports. Gynecol Oncol. 2005;96(2):539-42. [10] Ray K, Rocconi RP, Novak L, Straughn JM, Jr. Recurrence of endometrial adenocarcinoma in a prior Bartholin's cyst marsupialization incision. Gynecol Oncol. 2006;103(2):749-51.

[11] Harry VN, Shanbhag S, Lyall M, Narayansingh GV, Parkin DE. Isolated clear cell adenocarcinoma in scar endometriosis mimicking an incisional hernia. Obstet Gynecol. 2007;110(2 Pt 2):469-71.

[12] Watanabe Y, Nakajima H, Nozaki K, et al. Clinicopathologic and immunohistochemical features and microsatellite status of endometrial cancer of the uterine isthmus. Int $J$ Gynecol Pathol. 2001;20(4):368-73.

[13] Briet JM, Hollema H, Reesink N, et al. Lymphvascular space involvement: an independent prognostic factor in endometrial cancer. Gynecol Oncol. 2005;96(3):799-804.

[14] Honore LH, Hanson J. Statistical analysis of pathologic risk factors for 
intramyometrial lymphvascular space involvement in myoinvasive endometrial carcinoma. Int J Gynecol Cancer. 2006;16(3):1330-5.

[15] Creasman WT, Odicino F, Maisonneuve P, et al. Carcinoma of the corpus uteri. FIGO 6th Annual Report on the Results of Treatment in Gynecological Cancer. Int $J$ Gynaecol Obstet. 2006;95 Suppl 1:S105-43. 


\section{FIGURE LEGENDS}

\section{Figure 1. Magnetic Resonance Imaging of this case.}

Sagittal section (A) and axial section (B) of T2-weighed images: A low intensity lesion occupies the lower uterine cavity. Sagittal section of T1-weighed dynamic images (C): the border between the tumor and the endometrium is smooth.

Figure 2. Polypoid tumor growth at uterine isthmus and fundus.

Gross appearance (A). C-S scar stenosis was observed at uterine isthmus. Papillary tumor was predominantly located around this scar (B). Polypoid tumor protruded from the uterine fudus $(\mathrm{C})$.

Figure 3. Microscopic findings of well differentiated endometrioid adenocarcinoma at uterine fundus (A) and isthmus (B).

Grade-1 endometrioid adenocarcinoma next to the normal thickened endometrium (A) lacked a prominent myometrial invasion (C). Grade-1 endometrioid adenocarcinoma adjacent to the single layered endometrial cells at the C-S scar (D). Encroaching growth toward uterine cervix (E) and lymphovascular space involvement (F) of isthmus tumor. 
A

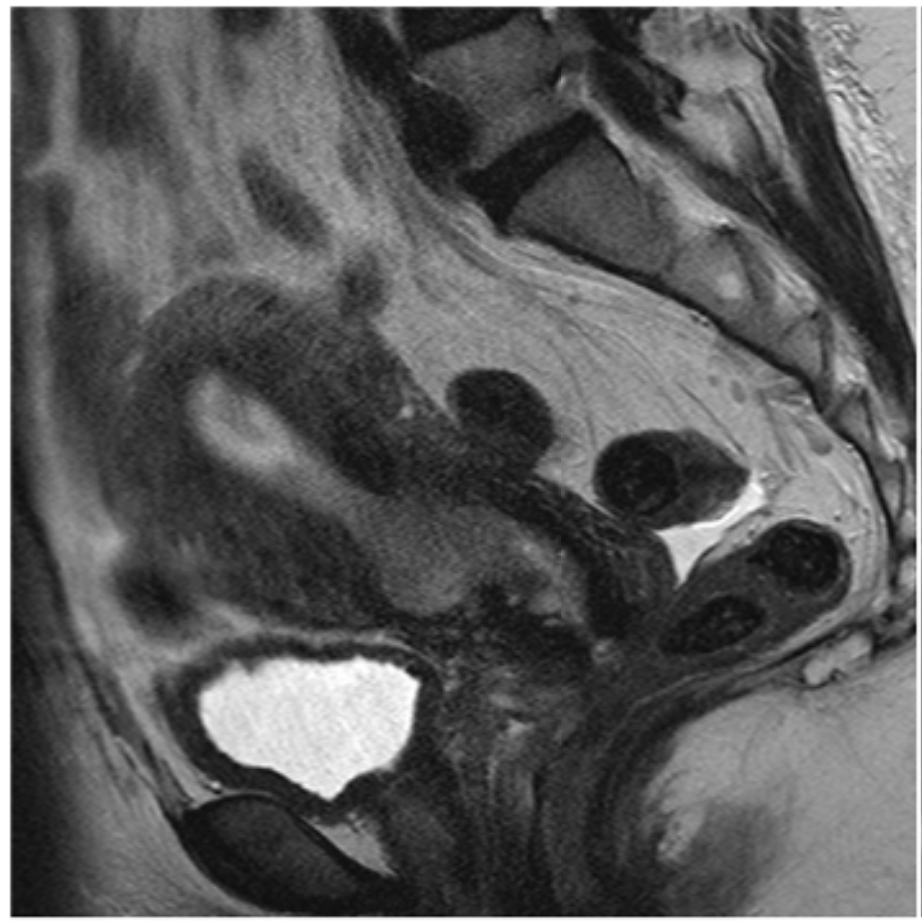

C

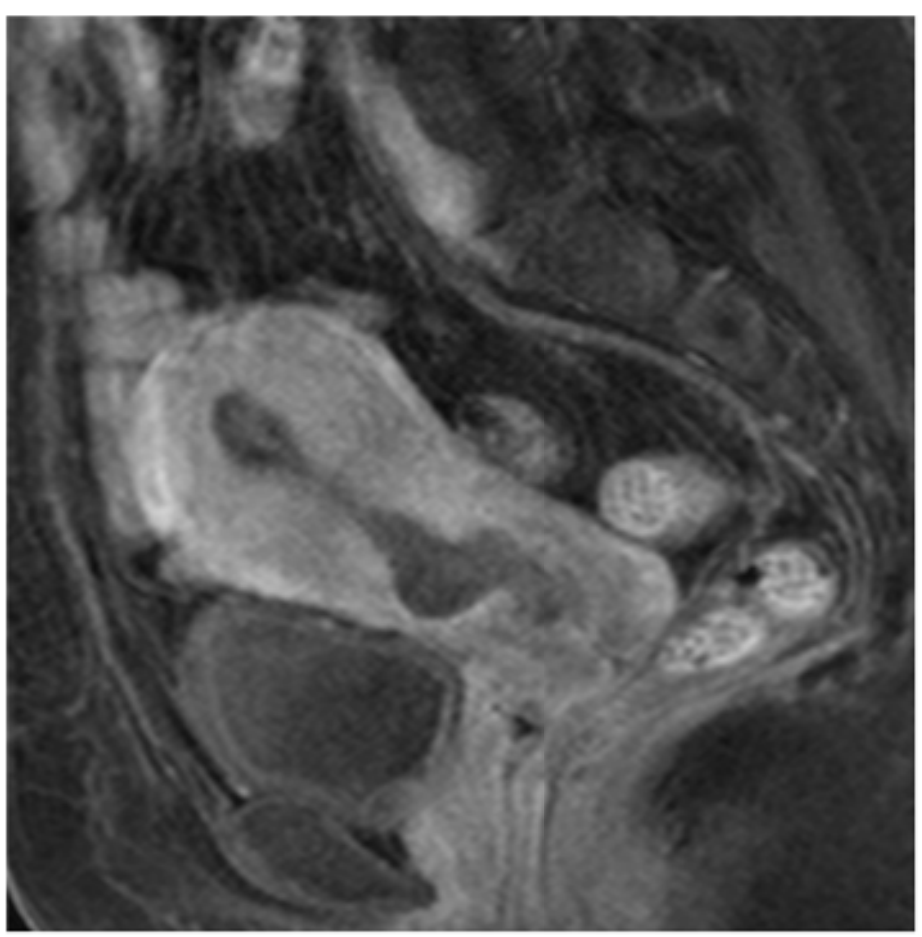

B

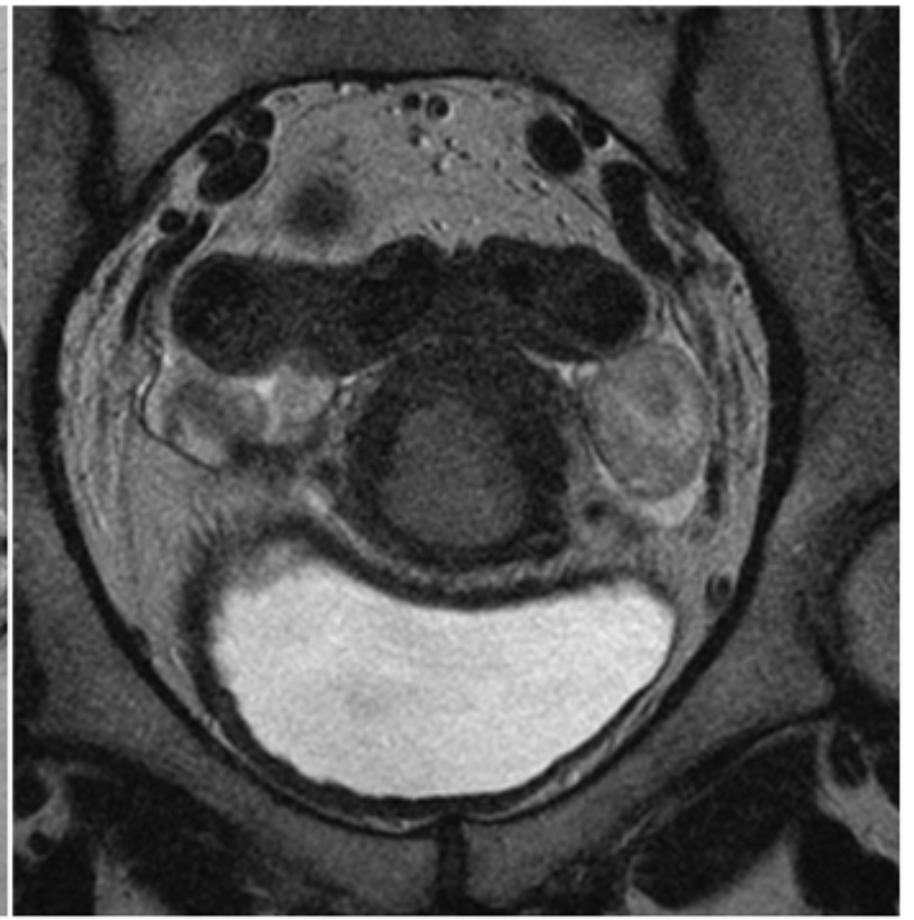

Figure 1 
A

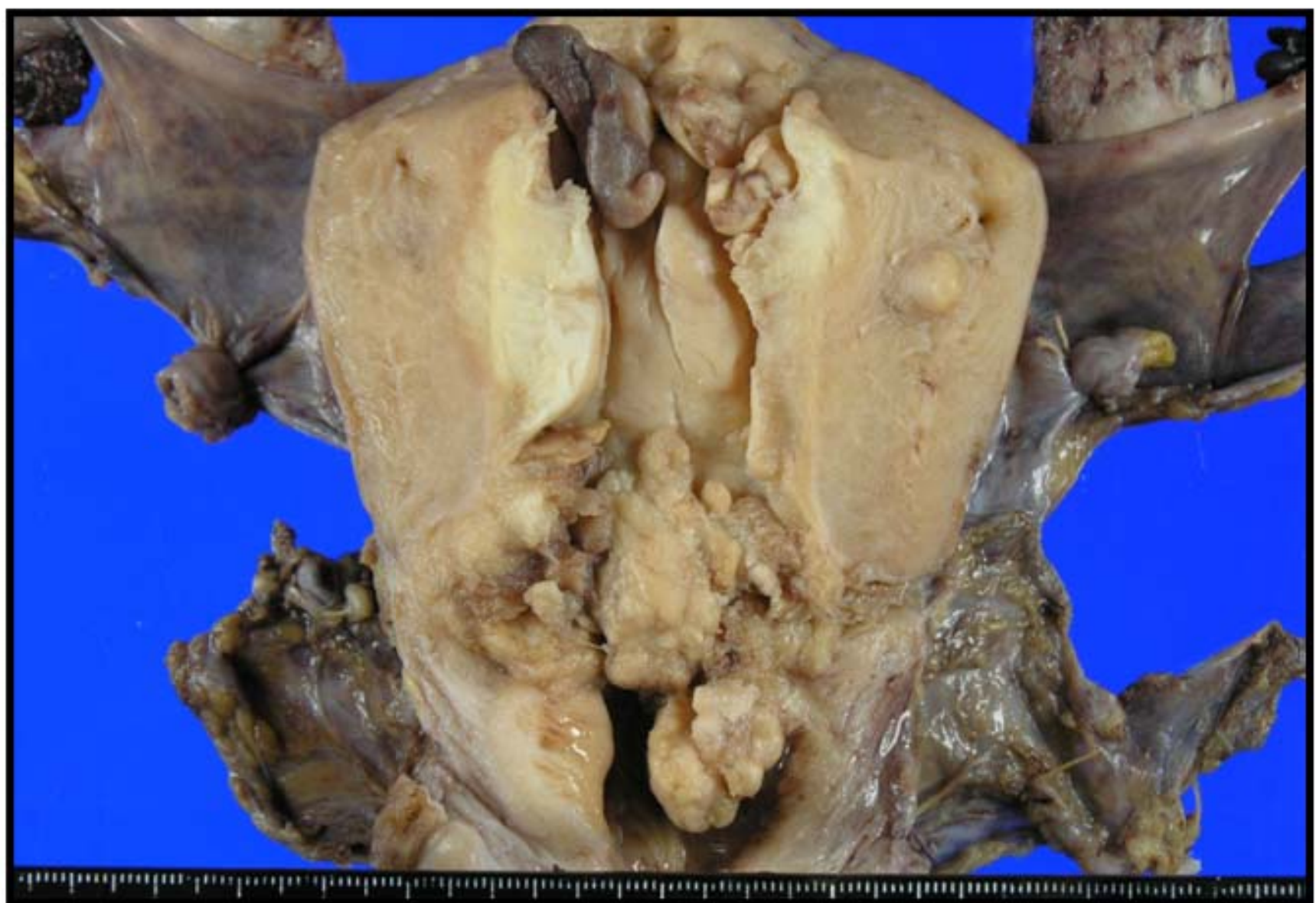

B

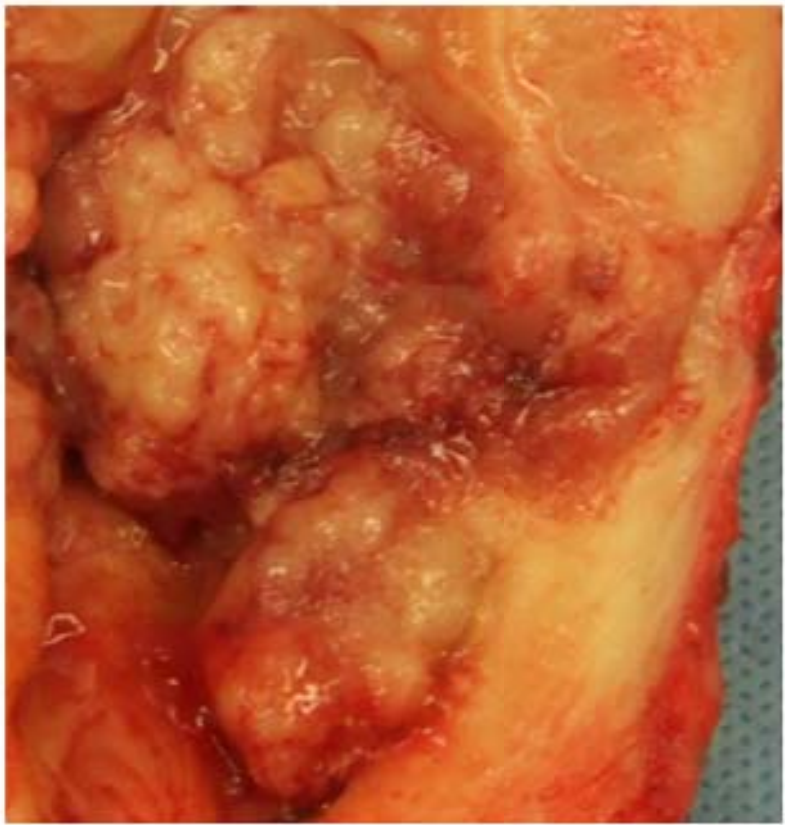

C

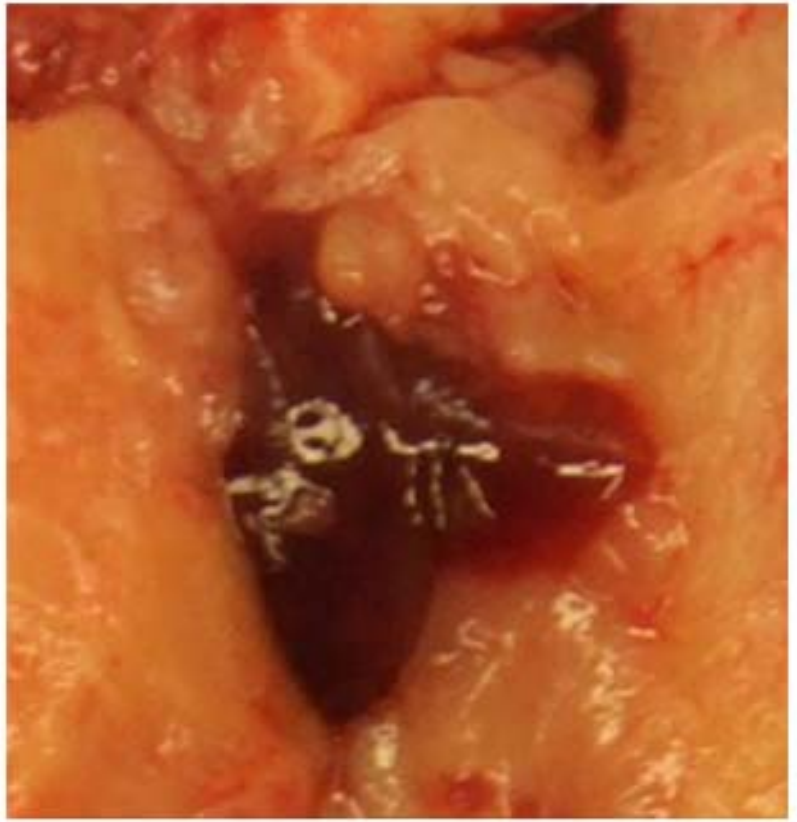

Figure 2 
A

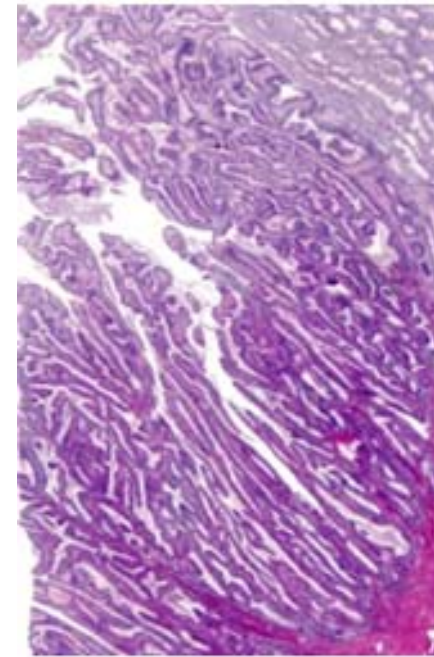

C

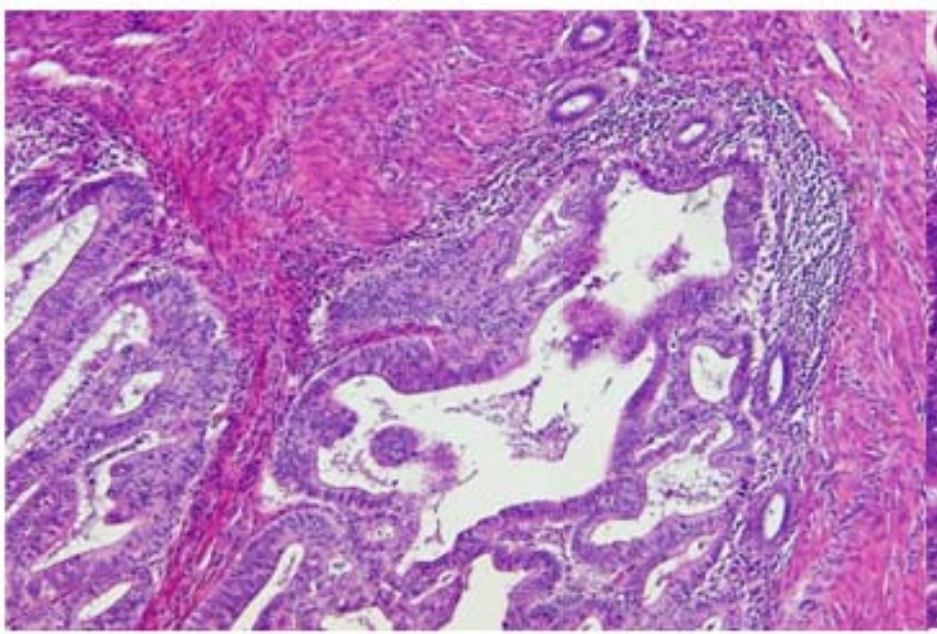

E

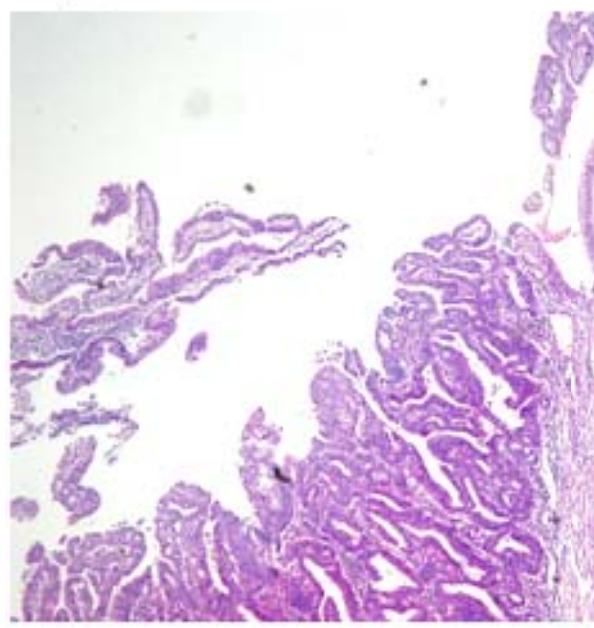

B

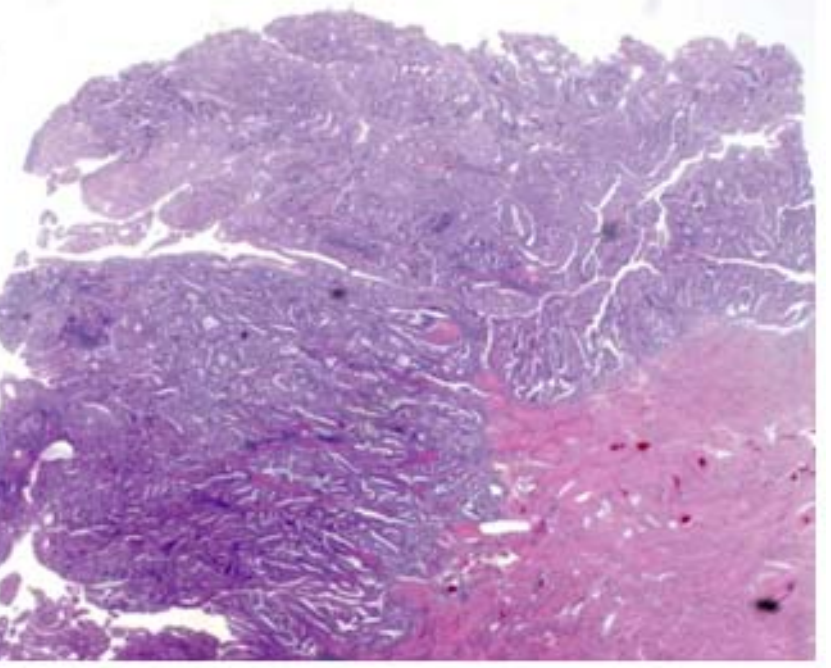

D

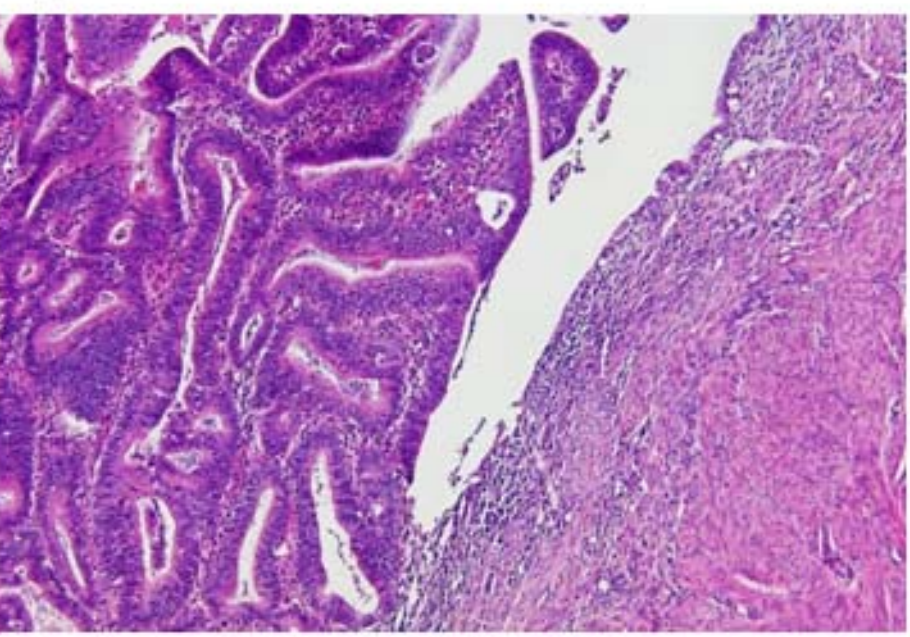

$\mathrm{F}$

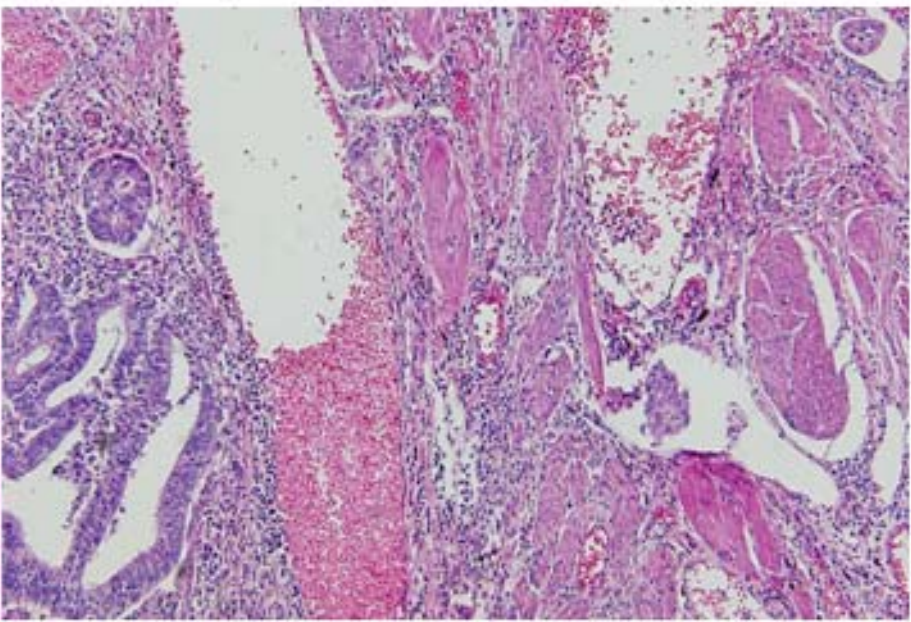

